\title{
Relationship between Arm Span Measurements and Body Height in Kolasin
}

\author{
Milos Kovacevic ${ }^{1}$ \\ 'University of Montenegro, Faculty for Sport and Physical Education, Niksic, Montenegro
}

\begin{abstract}
The unusual height of Montenegrin inhabitants of the highland region has been recognised by European anthropologists more than 100 years ago. In light of rather sparse recent scientific literature, the purpose of this research study was to examine the body height in both sexes of Montenegrin adults nowadays. Furthermore, the relationship between arm span and body height, which varies in different ethnic and racial groups, was used as an alternative to estimating the body height for some groups of the population. The nature and scope of this study analyses 55 adolescents ( 29 men, aged $18.17 \pm 0.38$ and 26 women, aged 18.15 \pm 0.36 ) from Kolasin. The anthropometric measurements were taken according to the protocol of the International Society for the Advancement of Kinanthropometry (ISAK). Means and standard deviations were obtained. A comparison of means of body heights and arm spans within and between the sexes were carried out using a t-test. The relationships between body height and arm span were determined using simple correlation coefficients and their 95\% confidence interval. A linear regression analysis was then performed to examine the extent to which arm span can reliably predict body height. The results have shown that male from Kolasin are $185.33 \pm 6.94$ centimetres tall and have an arm span of $186.91 \pm 9.48$ centimetres, while female from Kolasin are $169.82 \pm 7.09$ centimetres tall and have an arm span of $164.47 \pm 8.44$ centimetres. Comparing the results with other studies has shown that both sexes of Kolasin are very tall.
\end{abstract}

Key words: Prediction, Standing Height, Stature, Arm Span, Kolasin

\section{Uvod}

Crna Gora je zemlja u jugoistočnoj Evropi koja leži na obali Jadranskog mora. Graniči se na istoku i sjeveroistoku sa Srbijom, na zapadu i sjeverozapadu sa Hrvatskom i Bosnom i Hercegovinom i na jugoistoku sa Albanijom. Na jugozapadu je Jadransko more dijeli od Italije. Glavni, a ujedno i najveći grad je Podgorica, dok Cetinje ima status prijestonice. Crna Gora je postala nezavisna država na referendumu koji je održan 21. maja 2006 godine i tada je izašla iz državne zajednice sa susjednom Srbijom, što je predstavljalo i poslednje rasparčavanje nekadašnje Jugoslavije. Crna Gora obuhvata površinu od $13.812 \mathrm{~km}^{2}$. Zbog svoje vrlo neobične i može se reći veoma karakteristične reljefne strukture nudi i zimski i ljetnji turizam, jer izlazi na Jadransko more, a posjeduje i veliki broj planina od kojih su naj- poznatije Lovćen i Durmitor. Kao jedno od najprepoznatljivijih obilježija Crne Gore ističe se i rijeka Tara. Prema popisu iz 2011 godine (Monstat 2011) populacija Crne Gore je iznosila 620,029 stanovnika od čega su $50.61 \%$ žene, a 49.39\% muškarci. Osnovna etnička struktura Crne Gore je: 44.98\% čine Crnogorci, 28.73\% Srbi, 8.65\% su Bošnjaci i 4.91\% Albanci . Geografski gledano dijeli se na tri regije i to: južnu, srednju i sjevernu regiju. Uzorci korišteni u ovom istraživanju prikupljeni su u opštini Kolašin. Po veličini teritorije opština Kolašin zauzima šesto mjesto u Crnoj Gori sa površinom od $894 \mathrm{~km}^{2}$. Kolašin se prostire u gornjim i srednjim tokovima rijeka Tare i Morače. Okružen je planinskim grebenima i vrhovima planina: Sinjavine, Bjelasice, Komova i Vučja. Grad Kolašin su osnovali Turci 1651. kao svoje utvrđenje i karavansku stanicu od primorja prema sjeveru. Kolašinska

Correspondence:

\section{Montenegro M. Kovacevic}

Sport University of Montenegro, Faculty for Sport and Physical Education, Narodne omladine bb, 81400 Niksic, Montenegro E-Mail: mkocho994@gmail.com 
opština broji blizu 12000 stanovnika. Grad Kolašin kao sjedište opštine, sa prigradskim naseljima ima oko 6000 stanovnika. Područje Kolašina naseljavaju uglavnom Rovčani, Moračani, Vasojevići, Uskoci i doseljenici iz raznih krajeva. Kolašin geografski pripada sjevernoj oblasti Crne Gore.

Dinarski Alpi prepoznati su kao područje sa visokom populacijom od evropskih antropologa prije više od 100 godina (Bjelica et al. 2012; Mašanović, 2018a; Gardašević, Rašidagić, Krivokapić, Ćorluka i Bjelica, 2017; Pineau, Delamarche, \& Božinović, 2005). Imajući u vidu da savremeni Crnogorci, kao i drugi narodi sa prostora bivše Jugoslavije, spadaju više u dinarsku rasnu klasifikaciju nego u bilo koju drugu, istraživači ove studije pretpostavljali su da adolescenti sa prostora opštine Kolašin mogu biti malo viši ili jednako visoki kao i najviši stanovnici Crne Gore, samim tim bi se našli u društvu najviših nacija u Evropi (Bjelica et al. 2012; Popović, Bjelica, Molnar, Jakšić i Akpinar, 2013).

Neuobičajena visina crnogoraca je činjenica koja je primjećena od evropskih antropologa prije više od 100 godina. Uzorak od 800 crnogorskih muškaraca koji je mjerio Robert V. Ehrich početkom 20. vijeka davao je najveći prosijek u čitavoj Evropi $177 \mathrm{~cm}$, dok su neke oblasti imale tendenciju ka178 centimetara (Bjelica et al. 2012; Popović, 2016). U međuvremenu je sproveden veliki broj istraživanja te Crnogorci sada nisu najviši, ali su i dalje u samom vrhu.

Naučna literatura nam je pokazala da je mjerenje tjelesne visine izuzetno važna varijabla kada se procjenjuje nutritivni status (Arifi et al. 2017; Datta Banik, 2011), kada se procjenjuje rast djece, kada je potrebno ocjenjivanje osnovnih energetskih zahtjeva, prilagođavanje mjera fizičkog kapaciteta i predviđanje doziranja ljekova i postavljanje standarda fizioloških varijabli (npr. snaga mišića, brzina metabolizma, zapremine pluća i glomerularna filtracija). Međutim, tačan stepen ne može uvjek biti identifikovan i riješen na uobičajan način zbog raznih remetećih faktora kao što su na primer, paraliza, frakture, amputacija, skolioza i bol (Quanjer et al. 2014). Zbog ovog faktora, procjena tjelesne visine mora se dobiti na osnovu drugih pouzdanih antropometrijskih indikatoria kao što su dužina ruku i stopala (Agnihotri, Purwar, Googoolybe, Agnihotri, S i Jeebun, 2007; Arifi et al. 2017; Mašanović, Gardašević i Arifi, 2018a; Mašanović, Gardašević i Arifi, 2018b; Mašanović, Gardašević i Arifi, 2018c), visina koljena (Arifi et al. 2017; Karadag, Ozturk, Sener i Altuntas, 2012), dužina podlaktice (Arifi et al. 2017; Ilaiperuma, Nanayakkar i Palahepitiya, 2010), dužina grudnog koša (Arifi et al. 2017; Menezes et al., 2009), dužine kičmenog stuba (Arifi et al. 2017; Nagesh \& Pradeep Kumar, 2006), sjedeća visina (Arifi et al. 2017; Gardašević, 2018a; Mašanović, 2018b; Mašanović, Gardašević i Arifi, 2018d: Mašanović, Gardašević i Arifi, 2018e; Mašanović, Gardašević i Arifi, 2018f; Mašanović, Gardašević i Arifi, 2018g), dužina lopatice (Arifiet al. 2017; Campobasso et al., 1998), dužine tibije (Mašanović, 2018c; Gardašević, 2018b; Gardašević, Mašanović i Arifi, 2018a; Gardašević, Mašanović i Arifi, 2018b; Gardašević, Mašanović i Arifi, 2018c), raspona ru- ku (Arifi et al. 2017; Bjelica i sar., 2012; Popović i Bjelica, 2016; Popović, Bjelica, Milašinović, Gardašević i Rašidagić, 2016). Prema tome, svi navedeni antropometrijski indikatori, koji se koriste kao alternativa za procjenu relativne tjelesne visine, veoma su važni u svim slučajevima gore pobrojanim, a u kojima je tjelesna visina značajna te se ne može izmjeriti standardnom metodom. Takođe, važno je istaći da sve navedeno treba i mora primijeniti u sportskim naukama, budući da važnost tjelesne visine koja utiče na uspjeh u različitim sportskim disciplinama (Popović, 2017). Značajan je broj istraživanja koja su upućivala na korisnost primjenjivanja različitih tjelesnih parametara $\mathrm{u}$ procjenjivanju relativne tjelesne visine (Mašanović, 2017; Popovic, Arifi, \& Bjelica, 2017; Popović i Bjelica, 2017; Popović, Gardaševic, Mašanovic, Arifi, \& Bjelica, 2017), a ispostavilo se da je raspon ruku, upravo najpouzdaniji od svih ostalih (Mašanović, 2017).

Cilj ovog istraživanja bio je da se ispita tjelesna visina kod oba pola adolescenata opštine Kolašin, kao i da se utvrdi da li raspon ruku može biti adekvatna alternativna mjera za utvrđivanje relativne tjelesne visine.

\section{Metod}

U ovom istraživanju učestvovalo je ukupno 55 ispitanika (29 muškog i 26 ženskog pola) iz opštine Kolašin. Starost ispitanika kompletnog uzorka iznosi 18.16 \pm 0.37 , odnosno osobe muškog pola su bile prosječne starosti $18.17 \pm 0.38$, dok je prosječna starost osoba ženskog pola iznosila $18.15 \pm 0.36$ godina. Ključni kriterijumi za prihvatanje uzorka ispitanika muškog i ženskog pola bili su da: ispitanik dobrovoljno učestvuje u radu i da živi na prostoru opštine Kolašin.

Analiza je izvršena korišćenjem statističkog paketa za društvene nauke (SPSS) verzija 20.0. Srednja vrijednost i standardna devijacija raspona ruku i tjelesne visine, prikazana je za oba pola deskriptivnom statistikom. Za utvrđivanje statistički značajne razlike između oba pola u rasponu ruku i tjelesnoj visini, korišten je $\mathrm{t}$ - test. Odnosi između tjelesne visine i raspona ruku određeni su koeficijentom korelacije sa pouzdanošću od devedeset pet posto intervala. Zatim je izvršena analiza linearne regresije gdje rezultati pokazuju u kojoj mjeri se na osnovu raspona ruku može pouzdano predvidjeti tjelesna visina. Statistička značajnost je postavljena na $\mathrm{p}<0.05$.

\section{Rezultati}

Sažetakom podataka dobijeni su sledeći rezultati koji su prikazani u Tabeli 1. Dobijena srednja vrijednost raspona ruku kod muških ispitanika je $186.43 \pm 9.48 \mathrm{~cm}$ koji je $1.1 \pm 2.25$ veći od tjelesne visine i statistički ja značajan ( $\mathrm{t}=6.400 ; \mathrm{p}<0.000)$, dok za djevojke dobijena srednja vrijednost raspona ruku iznosi $164.47 \pm 8.48 \mathrm{~cm}$ i $5.33 \pm 1.39 \mathrm{~cm}$ je manji od srednje vrijednosti tjelesne visine i statistički je značajan $(\mathrm{t}=6.683, \mathrm{p}<0.000)$. Razlika između polova u rasponu ruku i tjelesnoj visini je takođe statističi značajna (tjelesna visina: $\mathrm{t}=68.158, \mathrm{p}<0.000$; raspon ruku: $\mathrm{t}=54.988, \mathrm{p}<0.000)$.

Tabela 1. Antropometrijski presjek ispitivanih osoba

\begin{tabular}{ccc}
\hline Ispitanici & $\begin{array}{c}\text { Tjelesna visina } \\
\text { (Srednja vrijednost } \pm \text { SD) }\end{array}$ & $\begin{array}{c}\text { Raspon ruku } \\
\text { (Srednja vrijednost } \pm \text { SD) }\end{array}$ \\
\hline Muškarci & $170.1-197.0$ & $165.0-203.0$ \\
& $(185.33 \pm 6.94)$ & $(186.43 \pm 9.48)$ \\
Žene & $151.0-183.0$ & $150.0-186.0$ \\
& $(169.82 \pm 7.09)$ & $(164.47 \pm 8.48)$ \\
\hline
\end{tabular}


U Tabeli 2. prikazan je koeficijent korelacije između varijabli koje su ispitivane. Ono što je pokazano ovom tabelom, jeste da postoji povezanosti između tjelesne visine i raspona ruku i da je ta povezanost značajna $(\mathrm{p}<0.000)$ i da je velika u ovome uzorku, bez obzira na pol (muškarci: 0.776; djevojke: 0.807).

Tabela 2. Koeficijent korelacije između tjelesne visine i raspona ruku kod ispitivanih osoba

\begin{tabular}{ccc}
\hline Ispitanici & Koeficijent korelacije & p-vrijednost \\
\hline Muškarci & 0.776 & $<0.000$ \\
Žene & 0.807 & $<0.000$ \\
\hline
\end{tabular}

Korelacija je značajna na nivou 0.01

Rezultati linearne regresione analize prikazani su u Tabeli 3. Prije svega ispitana je povezanost godina kao kovarijanse sa varijablama koje su ispitivane i utvrđeno je da godine nisu značajne i zbog toga su izostavljene iz dalje analize podataka. Analizom utvrđen je koeficijent regresije, koji iznosi 0.776 kod muškaraca, dok je kod osoba ženskog pola 0.807. To pokazuje da raspon ruku značajno predviđa tjelesnu visinu kod oba pola ispitanika opštine Kolašin, što potvrđuje koeficijent determinacije (\%) za muškarce (60.3) i za djevojke (65.0).

Tabela 3. Rezultati linearne regresione analize

\begin{tabular}{ccccc}
\hline Ispitanici & $\begin{array}{c}\text { Koeficijent } \\
\text { regresije }\end{array}$ & $\begin{array}{c}\text { Standardna } \\
\text { greska }\end{array}$ & R-kvadrat (\%) & t-vrijednost \\
\hline Muškarci & 0.776 & 4.46 & 60.3 & 6.400 \\
Žene & 0.807 & 4.27 & 65.0 & 6.683 \\
\hline
\end{tabular}

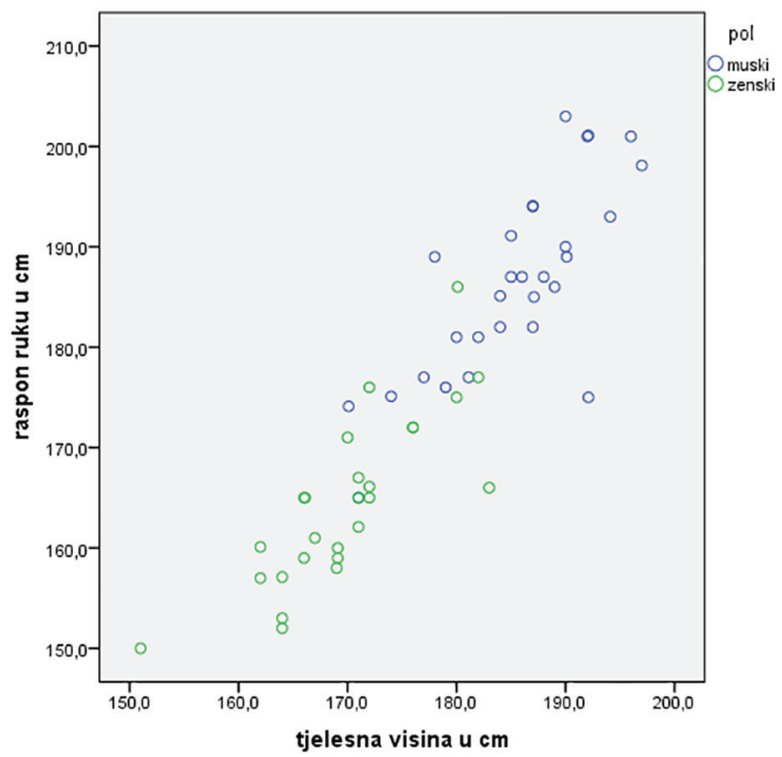

Diagram 1. Skater dijagram i veza izmedju raspona ruku i tjelesne visine kod oba pola

\section{Diskusija}

Ovim istraživanjem dobijeni su podaci koji pokazuju prosječnu visinu kod adolescenata oba pola građana opštine Kolašin i mogu biti korisni za upoređivanje sa drugim gradovima Crne Gore, izračunavanje prosjeka na nivou sjeverne regije kao i kompletne države. Rezultati su pokazali da su muškarci sa prostora opštine Kolašin prosječno visoki $185.33 \mathrm{~cm}$, dok im je prosječan raspon ruku $186.41 \mathrm{~cm}$. Dakle, uzimajući u obzir ovaj pokazatelj možemo zaključiti da su muškarci sa prostora opštine Kolašin vrlo visoki, odnosno viši od prosjeka koji važi za kompletnu mušku populaciju u Crnu Goru i iznosi $183.21 \mathrm{~cm}$, dok je respon ruku takođe viši od prosjeka koji je utvrđen na nivou Crne Gore, a koji iznosi $185.71 \mathrm{~cm}$ (Bjelica et al. 2012). Ako uporedimo prosjek ove studije sa skalom do koje je u svojem istraživanjiu došao Popović (2017) vidjećemo da se muški adolescenti sa područja opštine Kolašin nalaze na drugom mjestu po parametru prosječne tjelesne visine u okvi- ru 23 opštine u Crnoj Gori i to upravo iza prosjeka koji je dobijen mjerenjem kombinovanog uzorka na teritorijama opština Kolašin i Mojkovca, a koji je iznosio $185.51 \mathrm{~cm}$. Ako uporedimo rezultate ove studije sa prosjecima koji vladaju na nivou regija Crne Gore dobićemo sljedeće pokazatelje. Kolašinci su viši i od prosjeka koji važi za srednju regiju Crne Gore, a iznosi $183.66 \mathrm{~cm}$, dok je raspon ruku takođe viši od prosječnog srednje regije koji iznosi $184.91 \mathrm{~cm}$ (Vujović, Bubanja, Tanase i Milašinović, 2015), takođe Kolašinci su viši i od prosjeka koji je dobijen na prostoru južne regije Crne Gore, a iznosi $182.53 \mathrm{~cm}$, dok je raspon ruku nešto viši od prosječnog južne regije koji iznosi $184.55 \mathrm{~cm}$ (Milašinović, Popović, Matić, Gardašević i Bjelica 2016; Popović, Milašinović, Matić, Gardašević i Bjelica, 2016). Vrlo zanimljivo je da su muški adolescenti sa prostora opštine Kolašin viši od prosjeka koji važi za sjevernu regiju Crne Gore, koji iznosi $183.29 \mathrm{~cm}$, dok je raspon ruku viši od prosječnog sjeverne regije koji iznosi $184.29 \mathrm{~cm}$ (Popović, Bje- 
lica, Milašinović i Gardašević 2017; Milašinović, Gardašević i Bjelica, 2017). Ovakav rezultat ne čudi s obzirom da je Kolašin grad koji pripada upravo sjevernoj regiji Crne Gore, a polazeći od činjenice koju navode Milašinović, Gardašević i Bjelica (2017), a to je da najviši Crnogorci žive upravo na području sjeverne regije. Iako ovakve činjenice navode na zaključak da su adolescenti sa područja Kolašina najviši u Crnoj Gori, ovo ipak treba dodatno ispitati. Takođe u obzir se mora uzeti i činjenica da su u ovom istraživanju učestvovali adolescenti, što odmah navodi na činjenicu da njihov rast nije u potpunosti završen. Konstatacija koja je potvrđena u ovom istraživanju, a i svim istraživanjima koja su korištena zbog upoređivanja tjelesne visine i raspona ruku, glasi da je raspon ruku adekvatna alternativna mjera, na osnovu koje se vrlo pouzdano može izmjeriti relativna tjelesna visina muškaraca, a na osnovu ovog podatka može se predpostaviti da je i raspon ruku adolescenata sa područja opštine Kolašin najveći u Crnoj Gori.

Kada su u pitanju ispitanice, odnosno osobe ženskog pola sa područja opštine Kolašin, konstatovano je da njihova prosječna visina iznosi $169.82 \mathrm{~cm}$, što je više od prosjeka koji važi za žensku populaciju u Crnoj Gori, a iznosi $169.38 \mathrm{~cm}$ (Popović, 2017). Prosječan raspon ruku adolescentkinja opštine Kolašin iznosi $164.47 \mathrm{~cm}$. Ako se uporedi prosječna visina adolescentkinja opštine Kolašin sa prosjekom koji važi za svaku od regija Crne Gore dolazi se do saznanja da su Kolašinke više od prosjeka koji je dobijen za sjevernu regiju i iznosi $168.96 \mathrm{~cm}$, međutim to nije slučaj i sa prosječnim rasponom ruku adolescentkinja sjeverne regije koji iznosi $167.71 \mathrm{~cm}$ (Milašinović, Popović, Bjelica i Vasiljević, 2016), takođe više su i od prosjeka koji je dobijen u južnoj regiji, a koji iznosi $168.73 \mathrm{~cm}$, dok je raspon ruku adolescentkinja opštine Kolašin niži od prosječnog južne regije koji iznosi $167.23 \mathrm{~cm}$ (Milašinović, Popović, Jakšić, Vasiljević i Bjelica, 2016; Popović, Milašinović, Jakšić, Vasiljević i Bjelica, 2016). Kada je u pitanju srednja regija adolescentkinje sa područja opštine Kolašin su više od prosjeka srednje regije koji iznosi $169.24 \mathrm{~cm}$, a raspon ruku je niži od prosjeka srednje regije koji iznosi $168.03 \mathrm{~cm}$ (Bubanja, Vujović, Tanase, Hadžić i Milašinović, 2015).

Kao zaključak nameće se konstatacija koja je potvrđena u ovom istraživanju, a i svim istraživanjima koja su korištena zbog upoređivanja tjelesne visine i raspona ruku, i glasi da je raspon ruku adekvatna alternativna mjera, na osnovu koje se vrlo pouzdano može predvidjeti tjelesna visina osoba ženskog pola.

Takođe, vrlo zanimljivo je uporediti prosječnu visinu i raspon ruku adolescenata opštine Kolašin kao potencijalno najviših u Crnoj Gori sa prosjecima okolnih država. Prema istraživanju koje su sproveli Popović et al. (2013) prosječna visina maturanata u Srbiji iznosi $181.96 \mathrm{~cm}$, dok njihov prosječan raspon ruku iznosi $184.78 \mathrm{~cm}$, te se može konstatovati da su adolescenti sa prostora opštine Kolašin sa prosječnom visinom od $185.35 \mathrm{~cm}$ i prosječnim rasponom ruku od $186.41 \mathrm{~cm}$ u oba parametra napredniji i to osjetno.

Arifi et al. (2017) sproveli su istražvanje kojim su utvrdili da su muškarci na Kosovu prosječno visoki $179.52 \mathrm{~cm}$, dok im je prosječan raspon ruku $181.29 \mathrm{~cm}$, te se može konstatovati da su adolescenti sa prostora opštine Kolašin sa prosječnom visinom od $185,33 \mathrm{~cm}$ i prosječnim rasponom ruku od $186.41 \mathrm{~cm}$ u oba parametra znatno napredniji.

Popović, Bjelica, Georgijev, Krivokapić i Milašinović (2016) sproveli su istraživanje kojim su utvrdili povezanost raspona ruku sa visinom tijela i njihovi rezultati govore da je prosječna visina starijih makedonaca $178.10 \mathrm{~cm}$ i raspon ruku $178.78 \mathrm{~cm}$, te se može konstatovati da su adolescenti sa prostora opštine Kolašin sa prosječnom visinom od $185.35 \mathrm{~cm}$ i prosječnim rasponom ruku od $186.41 \mathrm{~cm} \mathrm{u} \mathrm{oba} \mathrm{parametra} \mathrm{na-}$ predniji i to osjetno.

Popović, Bjelica, Tanase i Milašinović (2015) sproveli su istraživanje kojim su utvrdili povezanost raspona ruku sa visinom tijela i njihovi rezultati govore da je prosječna visina muškaraca u Bosni i Hercegovini (istraživanje sprovedeno na univerzitetu u Banja Luci) $183.87 \mathrm{~cm}$, a raspon ruku $184.50 \mathrm{~cm}$, što dakle govori da su adolescenti sa prostora opštine Kolašin sa prosječnom visinom od $185.33 \mathrm{~cm}$ i prosječnim rasponom ruku od $186.41 \mathrm{~cm}$ u oba parametra u prednosti.

Kao krajnji zaključak ovog istraživanja može se navesti da su očekivanja koja su postavljena i ispunjena, odnosno potvrđeno je da je raspon ruku adekvatna alternativna mjera relativne tjelesne visini kod oba pola adolescenata opštine Kolašin. Takođe potvrđena je činjenica da su muški adolescenti među njavišima, ako ne i najviši u Crnoj Gori, a samim tim konkurentni su i na nivou Evrope, dok su ženski adolescenti na trećem mjestu u okviru kompletne Crne Gore.

Ovo istraživanje može poslužiti istraživačima kao primjer, zatim može biti relevantno za upoređivanje rezultata istraživačima koji se bave sličnom temom. Takođe rezultati ovog istraživanja mogu poslužiti za izračunavanje prosjeka na nivou kompletne Crne Gore ili regije kojoj grad Kolašin pripada. Osim naučnog ovo istraživanje može se koristiti i u zdrastvenom domenu kao izvor alternativnih načina za mjerenje tjelesne visine u situacijama kada je nije moguće izmjeriti na standardan način. Osim toga vrlo zanimljiva je i činjenica koja navodi na to da su Kolašinci potencijalno najviši u Crnoj Gori i ona može dati podstrek za nova istraživanja koja bi potvrdila njihov status u okvirima države ali i ispitala da li su najviši i u širim okvirima.

\section{Acknowledgements}

There are no acknowledgements.

\section{Conflict of Interest}

The authors declare that there are no conflict of interest.

Received: 29 March 2018| Accepted: 18 May 2018| Published: 13 July 2018

\section{References}

Agnihotri, A. K., Purwar, B., Googoolybe, K., Agnihotri, S., \& Jeebun, N. (2007). Estimation of stature by foot length. J. Forensic Leg. Med. 14(5), 279-83.

Arifi, F., Bjelica, D., Sermaxhaj, S., Gardasevic, J., Kezunovic, M., \& Popovic, S. (2017). Stature and its Estimation Utilizing Arm Span Measurements in Kosovan Adults: National Survey. International Journal of Morphology, 35(3), 1161-7.

Bjelica, D., Popovic, S., Kezunovic, M., Petkovic, J., Jurak, G. \& Grasgruber, P. (2012). Body Height and Its Estimation Utilizing Arm Span Measurements in Montenegrin Adults. Anthropological Notebooks, 18(2), 69-83.

Bubanja, M., Vujovic, D., Tanase, G. D., Hadzic, R., \& Milasinovic, R. (2015). Body Height and Its Estimation Utilizing Arm Span Measurements in Female Adolescents from Central Region in Montenegro. Sport Mont, 12(43-45), 277-82.

Campobasso, C. P., Di Vella, G., \& Introna, F. Jr. (1998). Using scapular measurements in regression formulae for the estimation of stature. Boll. Soc. Ital. Biol. Sper. 74(7-8)75-82.

Datta Banik, S. (2011). Arm span as a proxy measure for height and estimation of nutritional status: a study among Dhimals of Darjeeling in West Bengal India. Ann. Hum. Biol. 38(6), 728-35.

Gardasevic, J. (2018a). Standing Height/Sitting Height Ration in Eastern-Kosovan Adolescents. Retrieved from SSRN's eLibrary: https://ssrn.com/ abstract $=3141566$

Gardasevic, J. (2018b). Standing Height/Tibia Length Ration in Western-Kosovan Adolescents. Retrieved from SSRN's eLibrary: https://ssrn.com/ 
abstract $=3138101$

Gardasevic, J., Masanovic, B., Arifi, F. (2018a). Relationship Tibia Length/Standing Height in Central-Kosovan Adolescents. Retrieved from SSRN's eLibrary: https://ssrn.com/abstract=3138122

Gardasevic, J., Masanovic, B., Arifi, F. (2018b). Relationship Tibia Length/Standing Height in Northern-Kosovan Adolescents. Retrieved from SSRN's eLibrary: https://ssrn.com/abstract=3138112

Gardasevic, J., Masanovic, B., Arifi, F. (2018c). Relationship Tibia Length/Standing Height in Southern-Kosovan Adolescents. Retrieved from SSRN's eLibrary: https://ssrn.com/abstract=3138105

Gardasevic, J., Rasidagic, F., Krivokapic, D., Corluka, M., \& Bjelica, D. (2017). Stature and Its Estimation Utilizing Arm Span Measurements in Male Adolescents from Herzeg-Bosnia Entity in Bosnia and Herzegovina. Montenegrin Journal of Sports Science and Medicine, 6(1), 37-44.

Ilayperuma, I., Nanayakkara, G., \& Palahepitiya, N. (2010). A model for the estimation of personal stature from the length of forearm. Int. J. Morphol. 28(4), 1081-6.

Karadag, B., Ozturk, A. O., Sener, N., \& Altuntas, Y. (2012) Use of knee height for the estimation of stature in elderly Turkish people and their relationship with cardiometabolic risk factors. Arch. Gerontiol. Germatr. 54(1), 82-9.

Masanovic, B. (2017). Relationship between arm span measurements and body height in Dinaric Alpes population: A systematic review. Journal of Anthropology of Sport and Physical Education, 1(1), 33-7.doi: 10.26773/ jaspe.171006

Masanovic, B. (2018a). Standing Height and its Estimation Utilizing Arm Spam and Foot Length Measurements in Dinaric Alps Population: A Systematic Review. Sport Mont 16(2), 1-6.

Masanovic, B. (2018b). Standing Height/Sitting Height Relationhip in Western Region in Kosovo. Retrieved from SSRN's eLibrary: https://ssrn. com/abstract $=3138518$

Masanovic, B. (2018c). Tibia Length and Standing Heigh Relationshipt in Eastern Region of Kosovo. Retrieved from SSRN's eLibrary: https://ssrn. com/abstract $=3143118$

Masanovic, B., Gardasevic, J., \& Arifi, F. (2018a). Relationship between foot length measurements and body height: $A$ prospective regional study among adolescents in eastern region of Kosovo. Sport Mont, 16(1), 9-13. doi: $10.26773 / \mathrm{smj}$.180202.

Masanovic, B., Gardasevic, J., \& Arifi, F. (2018b). Relationship between Foot Length Measurements and Body Height: A Prospective Regional Study among Adolescents in Northern Region of Kosovo. Anthropologie-International Journal of Human Diversity and Evolution, in pres, https:// doi.org/10.26720/anthro.18.01.23.1

Masanovic, B., Gardasevic, J., \& Arifi, F. (2018c). Relationship between Foot Length Measurements and Body Height: A Prospective Regional Study among Adolescents in Central Region of Kosovo. Journal of Contemporary Medical Sciences, in press

Masanovic, B., Gardasevic, J., \& Arifi, F. (2018d). Standing Height and its Estimation Utilizing Foot Length Measurements in Adolescents from Southern Region in Kosovo. Sport Mont, 16(2), in press

Masanovic, B., Gardasevic, J., \& Arifi, F. (2018e). Sitting Height/Standing Height Relationship in Southern Region of Kosovo. Retrieved from SSRN's eLibrary: https://ssrn.com/abstract=3138523

Masanovic, B., Gardasevic, J., \& Arifi, F. (2018f). Sitting Height/Standing Height Relations in Central Region of Kosovo. Retrieved from SSRN's eLibrary: https://ssrn.com/abstract=3138525

Masanovic, B., Gardasevic, J., \& Arifi, F. (2018g). Sitting Height/Standing Height Relationship Measurements in Northern Region of Kosovo. Retrieved from SSRN's eLibrary: https://ssrn.com/abstract=3138526

Menezes, R. G., Kanchan, T., Kumar, G. P., Rao. P. P., Lobo, S. W., Uzsal, S.,Krishan, K., Kalthur, S. G., Nagesh, K. R., \& Shettigar, S. (2009). Stature estimation from the length of the sternum in South Indian males: a preliminary stady. J. Formensic Leg. Med. 16(8), 441-3.

Milasinovic, R., Popovic, S., Jaksic, D., Vasilejvic, I. \& Bjelica, D. (2016). Stature and its Estimation Utilizing Arm Span Measurements in Feale Adolescents from Southern Region in Montenegro. Sport Mont, 14(3), 15-8.

Milasinovic, R., Popovic, S., Matic, R., Gardasevic, J. \& Bjelica, D. (2016). Body Height and its Estimation Utilizing Arm Span Measurements in Male Adolescents from Southern Region in Montenegro. Sport Mont, 14(2), 21-3.

Milašinović, R, Gardašević, J, \& Bjelica, D. (2017). Body height and its estimation utilizing arm span measurements in male adolescents from northern region in Montenegro. Arta Kinesiologica, 11(2), 75-80.

Milašinović, R., Popović, S., Bjelica, D., \& Vasiljević, I. (2016). Body height and its estimation utilizing arm span measurements in female adolescents from northern region in Montenegro. In Book of Abstracts of 4th International Scientific Conference "Exercise and Quality of Life" (39), Novi Sad: Faculty of Sport and Physical Education.

Nagesh, K. R., \& Pradeep Kumar, G.(2006). Estimation of stature from vertebral column length in South Indians. Leg. Med. 8(5):269-72.

Pineau, J. C., Delamarche, P., \& Bozinovic, S. (2005). Average height of adolescents in the Dinaric Alps. C. R. Biol., 328(9), 841-6.

Popovic, S. \& Bjelica, D. (2016). Body Height and its Estimation Utilizing Arm Span Measurements in Kosovan Adolescence: National Survey. In Abstract Book of International Eurasian Conference on Sport, Education, and Society (9), Antalya: International Science Culture and Sport Association.

Popovic, S. (2016). Body Height and its Estimation Utilizing Arm Span Measurements in Montenegrin Adults: National Survey. In Book of Summaries of 11th FIEP European Congress "Anthropological Aspects of Sport, Physical Education and Recreation" (5-6), Banjaluka: University of Banjaluka, Faculty of Physical Education and Sport.

Popovic, S. (2017). Local Geographical Differences in Adult Body Height in Montenegro. Montenegrin Journal of Sports Science and Medicine, 6(1), 81-7.

Popovic, S. Gardasevic, J., Masanovic, B., Arifi, F., \& Bjelica, D. (2017a). Standing Height and its Estimation Utilizing Foot Length Measurements in Adolescents from Western Region in Kosovo. Sport Mont, 15(3), 3-7.

Popovic, S., \& Bjelica, D. (2017). Body Height and its Estimation Utilizing Foot Length Measurementsin Kosovan Adults: National Survey. In $A b-$ stract Book of the Sport Science Conference AESA 2017(2), Amol: Faculty of Sport Sciences, Shomal University; Asian Exerciseand Sp Science Association.

Popovic, S., Arifi, F., \& Bjelica, D. (2017). Standing Height and its Estimation Utilizing Foot Length Measurements in Kosovan Adults: National Survey. International Journal of Applied Exercise Physiology, 6(2), 1-7.

Popovic, S., Bjelica, D., Georgiev, G., Krivokapic, D., \& Milasinovic, R. (2016). Body Height and its Estimation Utilizing Arm Span Measurements in Macedonian Adults. Anthropologist, 24(3), 737-745.

Popovic, S., Bjelica, D., Molnar, S., Jaksic, D., \& Akpinar, S. (2013). Body Height and Its Estimation Utilizing Arm Span Measurements in Serbian Adults. International Journal of Morphology, 31(1), 271-279.

Popovic, S., Bjelica, D., Tanase, G.D. \& Milasinovic, R. (2015). Body Height and Its Estimation Utilizing Arm Span Measurements in Bosnian and Herzegovinian Adolescents. Montenegrin Journal of Sports Science and Medicine, 4(1), 29-36.

Popović, S., Bjelica, D., Milašinović, R., \& Gardašević, J. (2016). Body height and its estimation utilizing arm span measurements in male adolescents from northern region in Montenegro. In Book of Abstracts of 4th International Scientific Conference "Exercise and Quality of Life" (38), Novi Sad: Faculty of Sport and Physical Education.

Popović, S., Bjelica, D., Milašinović, R., Gardašević, J., \& Rašidagić, F. (2016). Body height and its estimation utilizing arm span measurements in male adolescents from Herzeg-Bosnia entity in Bosnia and Herzegovina. In Book of Abstracts of IUAES Inter Congress "World anthropologies and privatization of knowledge: engaging anthropology in public" (148), Dubrovnik: International Union of Anthropological and Ethnological Sciences.

Popović, S., Milašinović, R., Jakšić, D., Vasiljević, I.,\& Bjelica, D. (2016). Body height and its estimation utilizing arm span measurements in female adolescents from southern region in Montenegro. In Book of Abstracts of the 13th International Scientific Conference on Transformation Process in Sport "Sport Performance" (30), Podgorica: Montenegrin Sports Academy.

Popović, S., Milašinović, R., Matić, R., Gardašević, J.,\& Bjelica, D. (2016). Body height and its estimation utilizing arm span measurements in male adolescents from southern region in Montenegro. In Book of Abstracts of the 13th International Scientific Conference on Transformation Process in Sport "Sport Performance" (29-30), Podgorica: Montenegrin Sports Academy.

Quanjer, P.H., Capderou, A., Mazocioglu, M.M., Aggarwal, A., Popovic, S., Datta Banik, S., Tayie, F.A.K., Golshan, M., Ip, M.S.M., \& Zelter, M. (2014). All-age relationship between arm span and height in different ethnic groups. European Respiratory Journal, 44(4), 905-912.

Vujovic, D., Bubanja, M., Tanase, G. D. \& Milasinovic, R. (2015). Body Height and Its Estimation Utilizing Arm Span Measurements in Male Adolescents from Central Region in Montenegro. Sport Mont, 12(43-5), 283-8. 